\section{Cine experimental}

José Sarmiento

Creo que hablar de erotismo en el cine experimental contemporáneo es remitirnos a una buena parte de su historia. Hay mucha influencia del experimental de los sesenta y setenta, vertientes como el Pinku Eiga, con Wakamatsu como su máximo representante, que de por sí empezaba a derrumbar esos tabús existentes en el cine y que tuvo mucha influencia en el experimental más adelante. Uno de los padres del erotismo en el experimental fue Frans Zwartjes, dedicado a mostrar ese erotismo que era un poco obsesivo, insano, pervertido. El cineasta holandés, que fue en su época uno de los mejores cineastas experimentales, trabajó en filmes como Bedsitters o Audition este tema de la obsesión, la locura y el sexo. Kurt Kren y Otto Muehl, dentro del activismo vienés también fueron importantísimos, bordeando esta obsesión por lo erótico con lo escatológico.

Uno de los contemporáneos clave en lo que es el erotismo en el cine experimental vendría a ser Richard Kern, quizá conocido para algunos por un video que realizó para los recién formados Sonic Youth. Kern prácticamente ha dedicado su carrera a tratar el tema de la obscenidad y la perversión en casi toda su filmografía. Inclusive ahora, como fotógrafo, ha publicado un libro que trata prácticamente de fotografía pornográfica, a lo Hustler Magazine (action), acompañado de un DVD con las sesiones fotográficas (real action). Kern es el padre de la perversión, una mirada única y singular en el tema. Para verlo, uno debe despojarse de prejuicios, acceder a él sin ideas preconcebidas sobre la perversión y el erotismo. Así, el cine de Kern resulta casi natural, algo muy interesante de ver. Kern es conocido también por colaborar con artistas underground como Lydia Lunch (la reina del No Wave). Con ella hizo un cortometraje muy conocido y bastante erótico, The right side of my brain. Kern es el patriarca del cine experimental contemporáneo. Vale buscar su DVD The hardcore collection, que recopila sus mejores trabajos.
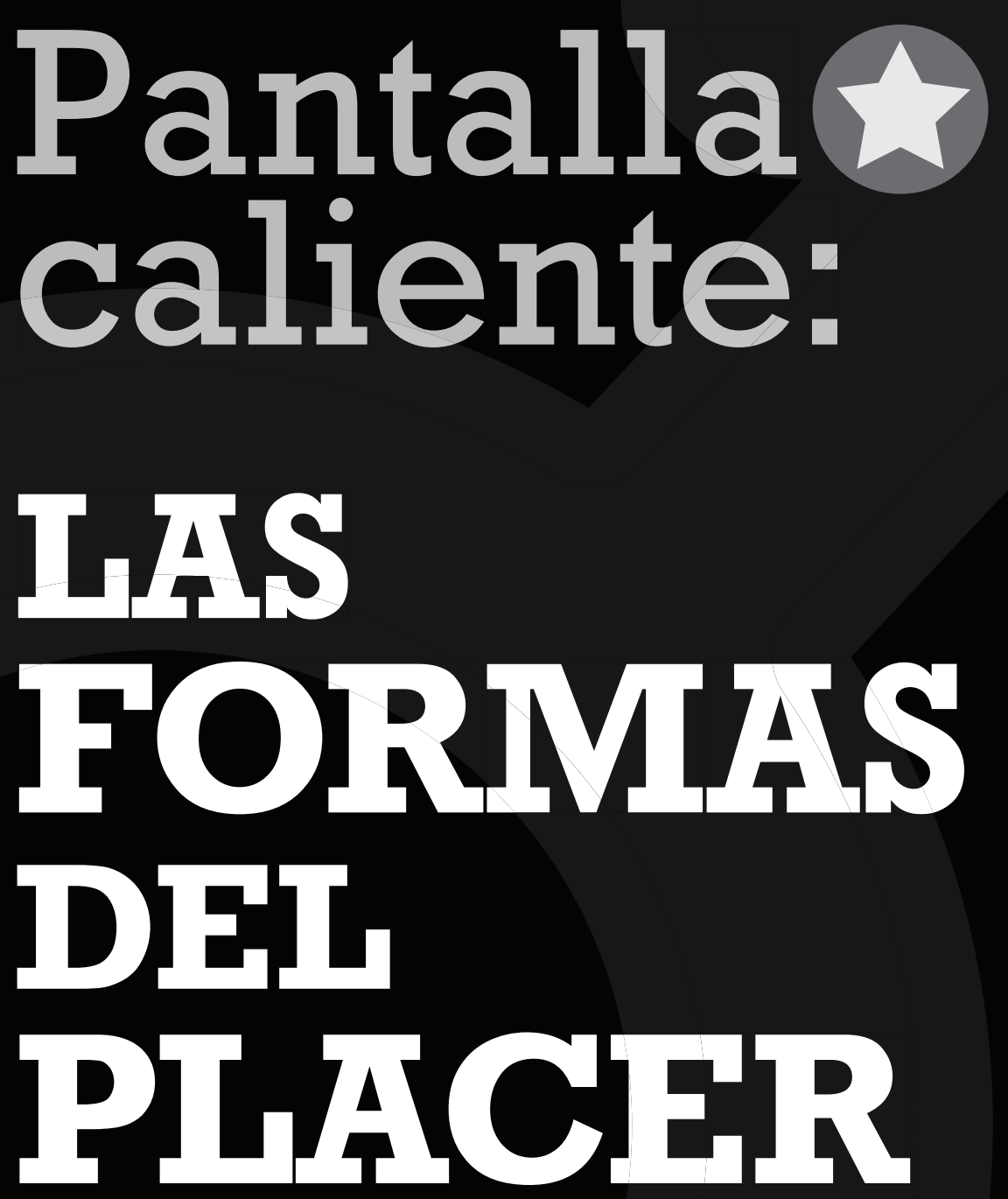

\section{Hablar de la animación o del} porno, o de lo experimental o lo indie, es hablar de cómo la pantalla gigante diversifica las formas en que el erotismo asoma ante nuestros ojos. 


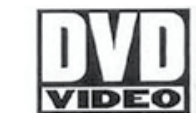

-

FOR MATUR AUDIEI ICES ONLY

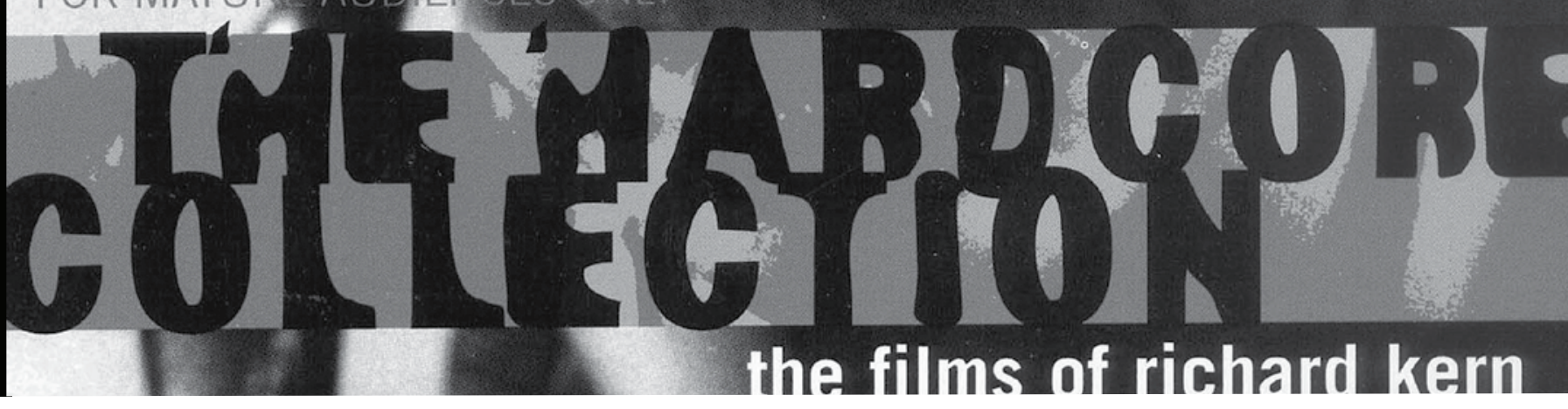


Por otro lado, la influencia de lo erótico en el experimental es inmensa porque el cine experimental como forma de cine que no atiende a convenciones narrativas tradicionales o del cine más mainstream, apela mucho a lo sensorial. Además, lo sensorial frente a lo hermenéutico o a lo que es lo interpretativo tiende ya a lo erótico, casi al espacio del puro goce, experiencia interior, erotismo puro. Como afirmaba Susan Sontag en su famoso Ensayo contra la interpretación, más que una hermenéutica del arte es una erótica del arte, inclinándose más a qué cosa nos hace sentir el arte. En ese aspecto el cine experimental trabaja mucho no con lo interpretativo, sino con lo sensorial (algo así como el expresionismo abstracto, por dar un ejemplo).

Sin lugar a dudas, creo que en los trabajos de casi todos los cineastas experimentales contemporáneos ha habido erotismo en algún momento. Por ejemplo, cineastas tan reconocidos como Peggy Ahwesh o $\mathrm{Su}$ Friedrich tienen una gran carga erótica en muchos de sus trabajos. Stan Brakhage también jugó con el tema: Wedlock house: An intercourse es un cortometraje dedicado a mostrar a Brakhage haciendo el amor con su mujer. Barbara Hammer es una de las cineastas de género gay más respetables dentro del cine experimental. Nitrate Kisses debe ser la piedra angular del cine queer experimental en el mundo. Por medio de retratos de parejas gay y su actividad sexual en cámara, además de expresar cómo esta sexualidad es vista y censurada desde fuera, Nitrate Kisses es el manifiesto de Hammer.

El movimiento Cinema of Transgression nos trajo también a cineastas como Nick Zedd y Tessa Hughes-Freeland, autora del famoso cortometraje Nymphomania, donde un fauno viola a un hada en el bosque. Esto está dentro de lo que se llamaba el cinema de transgresión, donde encontramos a un grupo de cineastas experimentales con bajo presupuesto que se dedicaron justamente a trabajar el tema de la obscenidad, la perversión y lo prohibido. En este grupo estuvo inscrito también Richard Kern.
A partir del nuevo milenio, el cine experimental no cuenta con un representante, digamos símbolo, como sucedió en las décadas pasadas. Sin embargo, conocemos y vemos el erotismo en el cine experimental de Oriente, en Tsai, en Weerasethakul, en el indie americano, The brown bunny de Gallo, y en otras corrientes del cine mundial. El erotismo ha quedado como una pulsión, una idea que se ejecuta de acuerdo con las sensibilidades de los cineastas contemporáneos.

Estoy seguro de que omito mucho, y olvido otro poco, pero pintar un panorama en un arte tan extenso como el cine es una tarea mayúscula. En los años por venir seguiremos encontrando nuevas propuestas, nuevos cineastas que nos sorprenderán tanto como lo hicieron los antiguos en algún momento.

\section{Cine de animación}

Antonio Espinoza

La animación no es un mundo exclusivamente infantil. Si hablamos de dibujos eróticos, no se puede dejar de mencionar al hentai japonés, género que goza de gran popularidad entre el erotismo en la animación. El punto de inicio de esta corriente puede ser señalado en el trabajo de Osamu Tezuka, quien también es considerado como el padre del manga y comic japonés, por medio de su anime Kureopatora o Cleopatra: Queen of sex (1970), que en su momento, en Estados Unidos, fue clasificado como un filme de categoría $\mathrm{X}$.

Otros casos importantes en el hentai son Bible black y Urotsukidoji. El primero se trata de un exitoso caso contemporáneo donde la historia gira en torno a la hechicería o magia negra y la sexualidad de un grupo de estudiantes. Una biblia negra satánica será el objeto que desata sobre los personajes hechizos y maldiciones sexuales, con motivo de rendir un culto diabólico. El segundo caso es un anime clásico que, gracias a su éxito, ha tenido varias secuelas, como Urotsukidoji II: La matriz del demonio. Se plantea un mundo de dioses y demonios donde prevalece la violencia extrema y las violaciones por tentáculos (lo que es frecuente en producciones japonesas debido a la censura impuesta en mostrar genitales). Es común en muchas películas hentai la aparición de hermafroditas, así como de mujeres chantajeadas sexualmente: reprimidas amas de casa, maestras de escuela con minifaldas de infarto, escolares de anatomías curvas y en desarrollo.

Sin embargo, este tipo de animación no es exclusiva de las producciones japonesas, ni se da solo en los últimos años. La primera película de esta índole puede rastrearse hasta Buried treasure, en la década de los veinte, la cual muestra un contenido abiertamente sexual para la época. Pese a su corta duración, se puede apreciar en una isla al personaje principal y a su miembro viril, que muestra un libre albedrío y la capacidad de desprenderse del cuerpo de su dueño, casi como un personaje aparte y con vida propia.

Una famosa película en los años setenta que se debe tomar en cuenta es Fritz, the cat, historia adaptada de un cómic de Robert Crumb con el mismo nombre. En ella se cuenta la vida de un gato depravado que tiene por intereses las drogas y el sexo. Como dato curioso, uno de los creadores de la película es Jim Davis, quien, más adelante, sería el creador de otro famoso gato de nombre Garfield.

Otra adaptación que daría que hablar en los ochenta sería la película animada Heavy metal, tomada de una revista de ciencia ficción. Incluso tendría una secuela, aunque muy por debajo de la original: Heavy metal 2000. La historia de violencia y sexo, ambientada en un contexto futurista, es relatada por una esfera verde, llamada Lornack, a la hija de un astronauta asesinado por aquel mismo elemento desconocido. $\mathrm{Mu}-$ chas figuras de mujeres de cuerpo pronunciadamente voluptuoso desfilan por la película.

En 1989, el maestro de la animación Jan Svankmajer dirigió Meat love, en la que se ven dos pedazos de carne animal que actúan humanamente y tienen sexo, para finalmente ser cocinadas en una sartén. Solo el director checo podía ser capaz de lograr una visión tan bizarra y delirante del erotismo.

En la actualidad, abundan en internet versiones no oficiales y porno- 

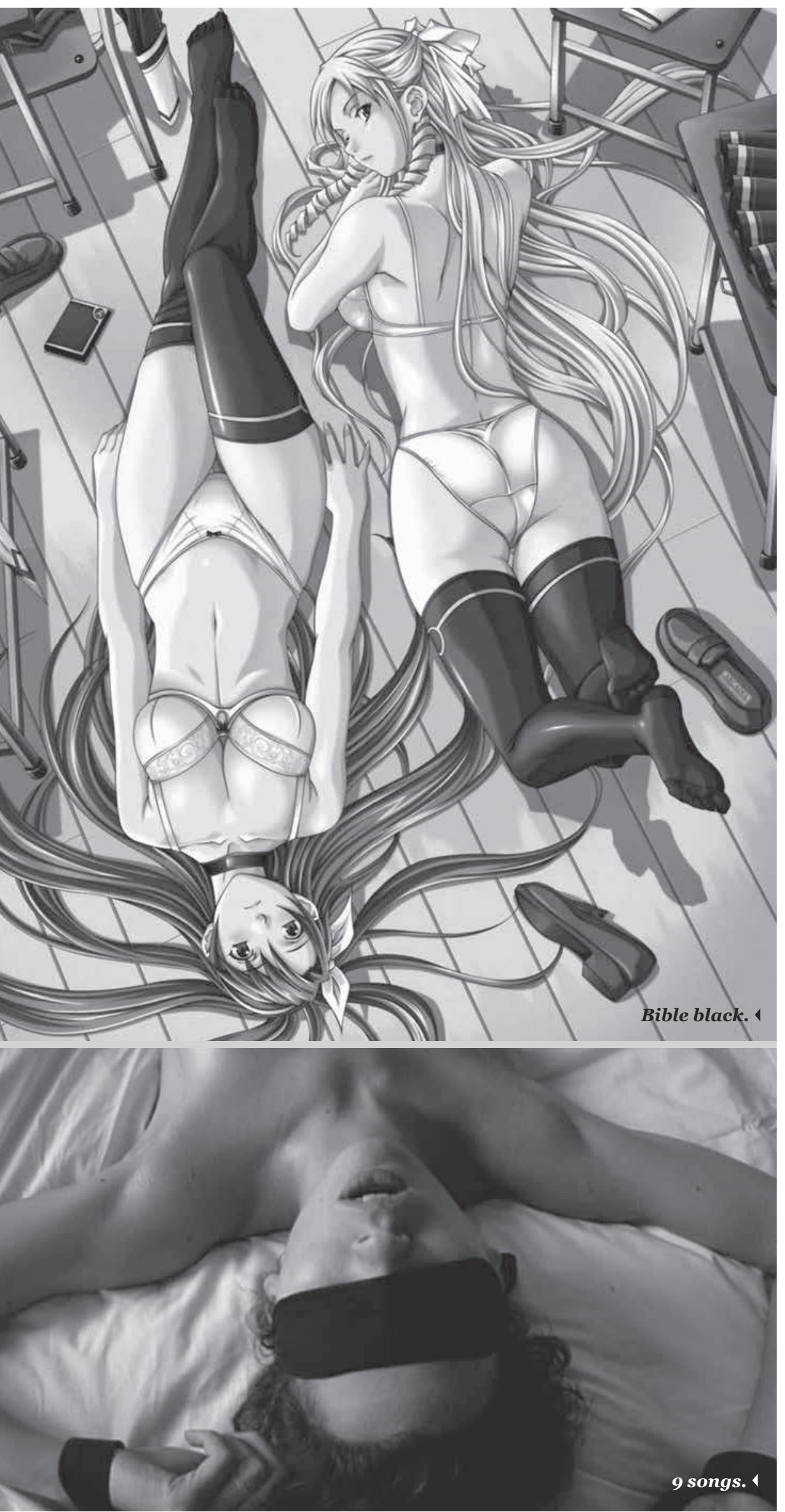

gráficas de dibujos animados clásicos de la televisión, como Scooby-doo o Dragon ball. Esas son las licencias de la fantasía erótica que permite la animación.

\section{Cine Indie}

Rodrigo Núñez Mas

La "moda" o estética indie se extendió por todas partes en los últimos años. De hecho puede reconocerse en muchas películas, sobre todo en lo que concierne a fotografía, vestuario y musicalización. Pero el erotismo no está muy presente en ellas, en realidad, la sexualidad es mostrada de modo más ingenuo e infantil, como en el caso de Juno (2007). Aunque una de las excepciones sería la $f e-$ llatio explícita, real, que le practica Chloë Sevigny a Vincent Gallo en The brown bunny (2003).

Pensando en eso, opto por referir en específico aquellas películas de contenido erótico que posean características de la cultura indie. En Shortbus (2006), de John Cameron Mitchell, por ejemplo, nos olvidamos del típico erotismo "sensual" o sugerente; observamos con humor a una generación sin tabús y exacerbada, donde cualquier opción sexual o fetiche ya es entendida naturalmente. Paralelamente, los personajes deben lidiar con sus tristezas y traumas. Es común encontrar un foco sentimental en lo indie; en Kissing on the mouth (2005) vemos a nerds con poca facilidad de interacción y, a través de su vida sexual, nos hablan de sus problemas personales con un estilo muy documental, muy «do it yourself».

Un ejemplo puramente erótico es 9 songs (2004), de Michael Winterbottom, centrado directamente en el acto sexual. En este caso vemos varios momentos de la historia de una pareja, que son divididos por canciones de rock indie. Es el recurso elegido por el director para darle ritmo a la historia, agregando intensidad a las escenas y completando su significado con las letras. La música se convierte en otro personaje.

Yendo por un lado más turbio, se podría considerar Ken Park (2002) de Larry Clark, por su atmósfera 
marginal con conflictos familiares, que envuelve a los adolescentes en la desadaptación, las drogas, el alcohol, etcétera. Hay una mirada más cruda y sincera de estos casi niños que viven libremente el amor y el sexo. En general, hay una tendencia a percibir la sociedad como un agente represor y perjudicial, que corrompe la sexualidad de las personas. Tal vez sea una generación que en su juventud percibió a su entorno de esa manera; en todo caso, ello parece generar un impulso a ir contra la marea y eliminar barreras. Se notan mentes más abiertas en los realizadores, donde no se juzga una relación por edades, número de integrantes ni género.

\section{Cine porno}

Antonio Espinoza

En la actualidad, el cine porno es una industria que mueve miles de millones de dólares al año y que tiene como su centro, tal como en el caso del cine convencional, a Estados Unidos. Esta expansión del cine porno y sus producciones se debe principalmente a la aparición del video digital e internet. Ambos elementos han facilitado el aumento de las producciones. El negocio principal de este cine está en grabar sus películas en video y comercializar los DVD, principalmente por internet. Volviéndose así en una experiencia privada y personal para el espectador.

Para el cine porno tanto la historia, la construcción de los personajes, los puntos de quiebre y los conflictos quedan en un segundo plano frente al único tema que mueve a este tipo de cine: el encuentro sexual de la pareja (como variante más común, pero no la única). De esta manera, el porno viene a ser un documental fisiológico donde toda la atención está puesta en registrar, con la máxima cercanía posible, la fellatio, el cunnilingus, el coito y las eyaculaciones. Incluso, muchos aspectos de la producción y el guion son descuidados por registrar la mejor performance sexual para la película, que es lo que básicamente busca el público consumidor. No obstante, hay algunas excepciones a la regla, como la trágica y "sartrea- na" El diablo en la señorita Jones (1972) - para muchos la mejor película porno de la historia-, de Gerard Damiano; la psicodélica Detrás de la puerta verde (1972), de los hermanos Mitchell; esa joya camp y cyberpunk llamada Cafe flesh (1982), de Rinse Dream; o Dog Walker (1993), de John Leslie, que por sus complejos juegos con el tiempo, con distintos planos de ficción y elementos del film noir, es un antecedente directo de lo que hizo David Lynch en Lost highway (1997).

Dentro de esta industria existe una gran variedad de categorías para todos los gustos, agregando elementos al clásico encuentro sexual entre hombre y mujer. Los más conocidos y aceptados socialmente son los tríos, los encuentros interraciales, el porno argumental, el gonzo y las escenas lésbicas. Sobre esta última categoría hay que mencionar que, incluso dentro del cine porno heterosexual, es muy común que haya una escena lésbica. Todo lo contrario, es imposible encontrar una escena gay en una producción heterosexual. Lo que habla del carácter machista de este cine. No obstante, como respuesta a eso, existe un cine feminista, aún muy escaso. Este tiene como una de sus mayores representantes a la directora Erika Lust, a quien le pertenecen títulos como Cinco historias para ellas o Life love lust.

Sin embargo, a pesar de algunas diferencias, la industria porno presenta y ha copiado ciertos patrones de la industria cinematográfica. Es así que el Valle de San Fernando, en Los Angeles (California), vendría a ser el Hollywood del porno. Además, el mundo del porno presenta su propio star system con actores y actrices que han aparecido en más de un centenar de películas. Algunas leyendas entre estos actores son los populares Rocco Siffredi y Nacho Vidal. Por el lado de las mujeres se puede citar a Jenna Jameson, Silvia Saint o Sasha Grey.

En el cine porno abundan las parodias. El cine más convencional ha sido una fuente de recursos e historias. De esta manera podemos encontrar títulos inspirados en famosas películas como Star wars $X X X$ : $A$ porn parody, Los picapiedras
XXX Parody, Batman XXX, Pulp friction, The big Lebowski $A X X X$ Parody y Scream XXX.

Asimismo, hay una inclinación en general hacia una estética más amateur en las producciones, sean estas de grandes productoras o de gente que recién está entrando en la industria. Gran parte de público muestra poco interés frente a producciones con un gran despliegue de recursos y que cuentan con la presencia de porn stars muy conocidas. En una búsqueda por lo real (o algo que se muestre menos actuado) se prefieren películas con actrices menos conocidas $o$ jovencitas amateurs que quieren iniciarse en este tipo de cine. Las cámaras escondidas, los falsos castings y los videos caseros entran en los nuevos gustos que mueven al cine porno. Se están dejando atrás los cuerpos perfectos y las performances exageradas. Es una apuesta que se aleja de la ficción y da un paso más hacia el documental. La cámara se convierte en espía y presencia el acto sexual, generalmente, desde una misma posición y sin realizar movimiento alguno. Esta nueva tendencia posibilita la intervención del público al grabar sus propias películas o escenas sexuales y divulgarlas en la red. Cuanta menos producción se evidencie mejor resultado tendrá. Es así que los audios poco claros y la iluminación natural priman en estas producciones.

Un cambio que se ha visto en los últimos años es que el acto sexual abandona la intimidad del dormitorio y ahora puede ser registrado en ambientes como escuelas, centros de trabajo, discotecas e incluso en ambientes abiertos, como un parque o una calle. Una corriente que busca responder a los nuevos intereses del público es el llamado Porn Art o X-Art, que viene a ser un cine porno softcore donde las actrices no son mujeres voluptuosas, sino que tienen el cuerpo de delgadas modelos. El acto sexual está privado de la exageración típica del porno y muestra más sensualidad y erotismo. Asimismo, no hay que olvidar los innumerables DVD de "porno interactivo", que le hacen competencia a la pornografía gratuita de internet, en los cuales las actrices mostradas en el televisor asumen las poses o actúan de la forma en que lo prefiera el consumidor, con solo apretar algunos botones de su control remoto. 


\section{ASCENSO Y CAÍDA DEL THRILLER ERÓTICO}

El thriller erótico tuvo sus mejores épocas en los años ochenta y noventa. A inicios de este nuevo milenio ha sido objeto de un menor interés, tanto por parte de realizadores como de cinéfilos. Muchos de sus personajes descienden a los infiernos, son seres órficos, que viven encantados por una presencia de aura sexual que los invita a jugar con la posibilidad de la muerte, a viajar a un Hades erótico. En Vestida para matar (1980), Kate Miller (Angie Dickinson), una mujer casada, tiene sexo con un desconocido y al regresar a buscarlo en su habitación para recoger el anillo de bodas que había olvidado, muere salvajemente, con cortes de navaja a manos de una misteriosa "dama". Jeffrey Beaumont (Kyle MacLachlan), el protagonista de Terciopelo azul (1986), es un joven que se obsesiona con una oreja mutilada y encontrada en un jardín, y al decidir investigar su origen, jugando a ser policía, conoce a una enloquecida cantante llamada Dorothy Vallens (Isabella Rossellini). Ingresa sigilosamente a su casa y se esconde en su closet, conociéndola por sorpresa e iniciando así un romance sadomasoquista, bajo la amenaza de ser descubierto por su amante, el peligroso gángster Frank Booth (Dennis Hopper). Estas películas, a pesar de los estilos que poseen, viniendo de dos cineastas tan distintos como Brian DePalma y David Lynch, oscilan sádicamente entre un suspense y un voyerismo de fuertes ecos hitchcockianos.

A fines de los ochenta e inicios de los noventa aparecieron más femme fatal que animaron el thriller erótico, como la inquietante Emmanuelle Seigner de Luna de hiel (1992) de
Roman Polanski, o la Sharon Stone que hace las veces de una novelista dispuesta a manipular a unos policías, enseñando fugazmente su vagina, en Bajos instintos (1992) de Paul Verhoeven -ver nota sobre el erotismo en su cine en la página 32-. Ellas se convierten en Eurídices tanáticas, dispuestas a dar una respuesta mortal al placer.

El éxito de aquel filme del realizador holandés permitió la aparición de numerosos thriller eróticos a lo largo de su década, como Sliver (1993) de Philip Noyce, Sin límites (1996) de los hermanos Wachowski o Criaturas salvajes (1998) de John McNaughton. Inclusive, algunos autores adaptaron el thriller erótico a su personal universo, como el David Cronenberg de Crash, extraños placeres (1996) o el Stanley Kubrick de Ojos bien cerrados (1999). Sin embargo, y a pesar de que el thriller erótico fue llevado a cabo por buenos directores entrando a este nuevo siglo, los resultados han sido, en líneas generales, desalentadores. Chen Kaige en Mátame suavemente (2002) y Jane Campion en En carne viva (2003) no son más que cintas recordadas por mostrar desnudos de dos actrices tan atractivas para muchos como Heather Graham y Meg Ryan. Las excepciones a la regla son Femme fatal (2002), en la que De Palma regresa al thriller erótico después de varios años, y la coproducción occidental/oriental Crimen y lujuria (2007) de Ang Lee, con sus imágenes lúbricas e intensas, dotadas de un sexo hasta cruel, casi pornográfico. Veamos si, en estos años, el thriller erótico recupera el interés y brillo de otros tiempos. 